\title{
Research on Measurement of Regional Differences and Decomposition of Influencing Factors of Carbon Emissions of China's Logistics Industry
}

\author{
$\operatorname{Ran} \mathrm{Li}^{1,2}$, Tao Sun ${ }^{1 *}$ \\ ${ }^{1}$ College of Economics and Management, Nanjing University of Aeronautics and Astronautics, Nanjing, Jiangsu, China; \\ No. 29 Jiangjun Avenue, Jiangning District, Nanjing, China \\ ${ }^{2}$ Jincheng College, Nanjing University of Aeronautics and Astronautics, Nanjing, Jiangsu, China; \\ 88 Hangjin Avenue, Lukou Street, Jiangning District, Nanjing, China
}

Received: 13 August 2020

Accepted: 10 November 2020

\begin{abstract}
Based on the energy consumption data of the logistics industry in 30 provinces and cities in China, this paper uses the carbon emission accounting method of IPCC to estimate the total carbon emissions of the logistics industry in China from 2010 to 2019, and introduces the carbon emission Theil index. The Logarithmic Mean Divisia Index (LMDI) model is used to measure the regional differences in carbon emissions of China's logistics industry and decompose the influencing factors. The research results show that the total carbon emissions of China's logistics industry have increased significantly, and the total carbon emissions and growth rates of the eastern region are significantly higher than those of the central and western regions. On the whole, the inter-provincial differences in carbon emissions of China's logistics industry have not changed substantially and have shown a downward trend. Intra-regional differences are the main reason for the overall difference in carbon emissions in China's logistics industry, and inter-regional differences have little impact on the overall difference. Among the three major regions, the eastern region has the largest inter-provincial carbon emissions difference, followed closely by the central region, with the western region having the smallest difference. Furthermore, the difference in carbon emissions between the eastern, central, and western regions is expanding, the results of the LMDI model show that the economic development effect is the most important positive effect of the logistics industry's carbon emissions in terms of the national average. The population scale effect is second, and the energy intensity effect is the main negative effect, followed by the energy structure effect. In terms of regional differences, the energy intensity effect is the most obvious in the eastern region, and the population scale effect has a relatively greater
\end{abstract}

*e-mail: taosnuaa@163.com 
impact on the western region. The effect of economic development on the eastern and western regions is higher than in the central region.

Keywords: logistics, carbon emissions, Theil index, LMDI, decomposition

\section{Introduction}

Global warming has been a focus of world attention in recent years and has mainly been attributed to the emission of greenhouse gases. The Fifth Assessment Report of the United Nations Government Panel on Climate Change (IPCC) in 2014 confirmed the existence of climate warming and, based on new scientific observations, more complete attribution analysis, and climate system model simulation results, it also confirmed the causal relationship between human activities and global climate warming. Moreover, carbon dioxide was identified as the main source of greenhouse gas emissions. China is a major energy consumer and also a major carbon emitter. Under the pressure of global warming, China is facing increasingly severe pressure to reduce emissions. According to statistics, China's carbon dioxide emissions were 9.893 billion tons in 2012, and China's carbon dioxide emissions accounted for nearly 30\% of the global total in 2019 . China has already far exceeded the carbon emissions of other countries [1]. At the 2009 Global Climate Conference held in Copenhagen, Denmark, developed countries, including the United States, and developing countries, including China, did not agree on how to solve the problem of carbon emissions. However, the Chinese government took responsibility for reducing global carbon emissions and promised that by 2020 carbon dioxide emissions per unit of GDP would be reduced by $40 \%$ to $45 \%$ from the 2005 level [2].

In recent years, logistics companies have entered a period of rapid development under the influence of economic globalization and the network economy. The logistics industry is a composite production service industry that integrates transportation, warehousing, freight forwarding, information and other industries, and is a basic and strategic industry that supports the development of the national economy. Accelerating the development of the modern logistics industry is of great significance for promoting industrial restructuring, transforming development methods, enhancing the competitiveness of the national economy, and building ecological civilization. According to statistics, in 2013, the total social value of logistics in China was 197.8 trillion yuan, and the added value of the logistics industry was 3.9 trillion yuan. With the price unchanged, it increased by $8.5 \%$ over the previous year. The added value of the logistics industry accounted for $6.8 \%$ of GDP and $14.8 \%$ of the added value of the service industry. Furthermore, the overall operation of the logistics industry appears to have good momentum [3]. The total output value of logistics increased from 981.793 billion yuan in 2004 to $3,158.523$ billion yuan in 2016, and its position in the national economy has continued to improve. The logistics industry is one of the biggest consumers of energy in China, particularly refined oil. Each year, the logistics industry consumes about $91.2 \%$ of the gasoline and $63 \%$ of the diesel in China, ranking first among all industries [4]. The amount of $\mathrm{CO}_{2}$ produced by logistics industry circulation and operations also accounts for a very large proportion of the industry total. In 2017, the logistics industry's carbon emissions accounted for about $20 \%$ of the country's total carbon emissions. At present, the carbon dioxide emissions of the logistics industry are increasing rapidly. The carbon dioxide emissions of China's logistics industry have increased from 307.8 million tons in 2004 to $997,684,300$ tons in 2019 , ranking first amongst all industries in terms of the growth rate of carbon dioxide emissions [5]. Therefore, studying the current status and characteristics of carbon emissions in China's logistics industry could play a vital role in reducing the intensity of carbon emissions. China has a vast territory, and there are substantial differences in the level of logistics development and the energy consumption structure in various regions. Scientific and accurate measurement and analysis of the differences and evolutionary trends of carbon emissions in the logistics industry in different regions is a fundamental prerequisite for scientifically formulating carbon emission reduction plans.

The research in the field of carbon emissions focuses on accounting methods, factor decomposition, and regional differences. For the calculation of carbon emissions, academia has explored many calculation methods. Peter et al. [6] used the IPCC inventory and modeling methods to calculate the carbon footprint of agricultural products. The research of Liptow et al. [7] based on the life cycle theory, used the recently proposed climate impact assessment method to evaluate biological basic products, and discuss carbon emissions during different life cycles. Some scholars used the IPCC method to estimate the total carbon emissions of various provinces in China [8-10]. Zhou et al. [11] used the direct energy consumption method of logistics operations to calculate the carbon dioxide emissions of the logistics industry in China in 2008 from the perspective of transportation energy consumption and transportation routes. Zhang and Cai [12] used IPCC's carbon emission accounting method to estimates the total carbon emissions of the logistics industry in various provinces and cities from 2003 to 2011. Based on the IPCC method, Jin et al. [13] estimated that the carbon emissions of all provinces and regions in China from 1992 to 2012 showed an increasing trend. Lenzen [14] used an input-output table to study the direct and 
indirect greenhouse gas emissions caused by Australian residents, and found that residents' contributions to greenhouse gas emissions mainly came from indirect energy consumption. Machado et al. [15] measured the direct and indirect carbon dioxide emissions of Brazil's non-energy export products, and noted that indirect carbon emissions accounted for a large proportion. Wei et al. [16] adopted the life cycle method to measure the energy consumption and carbon dioxide emissions of households. The study found that residents' indirect energy consumption was greater. Burchart-Korol [17] adopted the life cycle approach to evaluate the carbon emissions, and found that this method could help reduce carbon emissions. Bonilla et al. [18] analyzed the carbon emission levels of various sectors in the EU using data sets and environmental input-output tables of nine sectors, and found that the electronics and textile industries had the highest carbon emissions.

Studies of the decomposition of the influencing factors of carbon emissions have mainly applied the LMDI method. In the industrial field, Ang and Liu [19] used LMDI to analyze the main influencing factors of $\mathrm{CO}_{2}$ emissions in eight industrial sectors in China, and concluded that industrial added value and industry energy intensity are the main factors affecting carbon emissions. Chunbo and David [20] used LMDI technology to decompose the changes in energy intensity in China from 1980 to 2003, and found that technological innovation was the main cause of the decline in energy intensity. Claudia et al. [21] analyzed the change trend of $\mathrm{CO}_{2}$ emissions in Mexico's manufacturing industry using LMDI. Based on the influencing factors of manufacturing carbon emissions, it was concluded that the energy structure and energy intensity were the main factors affecting the carbon emissions of the industry. The influencing factors investigated by Chinese scholars have mainly included energy intensity effect, energy structure effect, industrial structure effect, per capita income, output scale effect, and energy emission intensity effect [22-23]. In research on the logistics industry, Zhang [24] decomposed the influencing factors into six effects: carbon emission factor, energy structure, energy intensity, economic development, logistics output, and population size. Ma and Wang [25] applied LMDI analysis of the influencing factors of the national logistics industry's carbon emissions from 1991 to 2010; results showed that economic growth was the main driving force of the logistics industry. Yuan and Zhang et al. [26] found that the energy structure and energy intensity had an inhibitory effect on carbon emissions in developed regions. Liu and Liu [27] used the LMDI method to decompose the driving factors of changes in carbon emissions in China's logistics industry, and analyzed the impact of energy structure, energy efficiency, and economic growth. Tang and Li [28] used logistics data of ten provinces and cities in eastern China from 2008 to 2010 as the research object, and undesired output of carbon dioxide emissions as an input variable. A three-stage Data Envelopment Analysis (DEA) model was used to measure and analyze the pure technical efficiency, scale efficiency, and overall efficiency of the logistics industry, and findings showed that the regional differences in carbon emissions were significant.

Foreign scholars noted regional differences in carbon emissions as early as the 1996 IPCC climate report. Subsequently, scholars have studied this problem and applied measures of income imbalance in their research. Roberto [29] used nuclear density estimation methods and a polarization index to study the polarization of carbon dioxide emissions per capita using the carbon emission levels of 87 countries as a sample. ClarkeSather et al. [30] used China's eastern, central, and western regions as samples, and a combination of the coefficient of variation, the Theil index, and the Gini coefficient to study the differences in regional GDP and per capita carbon emissions. Zhou et al. [31] used the DEA method to study the carbon dioxide emission characteristics of the transportation sectors of 30 provinces, cities, and autonomous regions in China (excluding Tibet, Hong Kong, Macao and Taiwan), and conducted a regional comparative analysis to obtain the carbon reduction of the transportation sector in the eastern region. Results showed reductions in the eastern region were more effective than those in the central and western regions. Yao et al. [32] explored the differences in the carbon emissions of G20 countries from 1971 to 2010 and concluded that the energy efficiency and carbon emissions of most advanced economies and some emerging economies had improved. Energy intensity has been found to be decreasing in some G20 countries while increasing in others, such as France, Mexico, and Brazil. Chinese scholars have mainly conducted research on the spatial distribution and regional differences of carbon emissions in the logistics industry. Liu et al. [33] found that China's eastern region accounted for the largest proportion of carbon emissions from 1998 to 2008, while the western region showed a gradually increasing trend and could be a key emission reduction area in the future. Zhang et al. [34] analyzed China according to the regional characteristics of carbon emissions, and concluded that the eastern region consistently records the greatest carbon emissions, carbon emissions in the central region are relatively stable, and carbon emissions in the western region are relatively small but maintain a continuous upward trend. Deng et al. [35] concluded from 1995 to 2010 that the effect of carbon emissions in the eight major regions of the country varied, and the energy structure effect has an inhibitory effect on the carbon emissions of economically developed regions. Zhang et al. [36] applied environmental production technology to analyze the dynamic changes of the carbon dioxide emissions of the logistics industry in 30 provinces, municipalities, and autonomous regions in China from 2003 to 2009 and conducted a comparative study of regional differences. 
A review and summary of the relevant literature on carbon emissions in the logistics industry in China and abroad shows that, from the perspective of the research scope, the focus of international research includes the global level, the European Union, G20 countries, and other regions. At the national level, research has been mainly concentrated in the United States, South Korea, China, and Japan. The content of research has focused on the four aspects of logistics industry carbon emission measurement methods, performance evaluation, decomposition of influencing factors, and low-carbon development strategies. Due to the gradual expansion of the research scope and research content, insights into the field of low-carbon logistics have been steadily enriched. This has important theoretical significance as a reference for the global logistics industry to achieve emission reduction.

There are some shortcomings in the existing research that require improvement, as follows: (1) Few empirical studies exist on carbon emissions from the perspective of the logistics industry. Empirical research is supported by data and, as a result, its findings are more convincing. Therefore, research methods should be more empirical; (2) Few studies exist of the carbon emissions of the logistics industry from the perspective of provinces; moreover, the existing studies only provide analysis of individual provinces. China has a large area, and each province has formulated its own policies in accordance with its specific situation. Thus, the study of spatial differences in each province is more meaningful for the implementation of emissions policies.

The main contributions of the thesis are: (1) Measure the carbon emissions of the logistics industry in different regions of China; (2) Based on the Theil index, analyze the differences between the three regions of China's logistics also carbon emissions and the differences within the regions, and respectively Explains the contribution of the two differences to the overall difference, and provides an empirical basis for a clear understanding of the differences between regions; (3) Based on the LMDI decomposition model, analyzes the main influencing factors of the logistics industry's carbon emissions, and grasps the logistics industry's carbon emissions. Regional characteristics provide a practical basis for the government to adopt corresponding policies.

\section{Material and Methods}

\section{IPCC Measurement Method for Carbon Emissions}

According to the estimation method provided by the United Nations Intergovernmental Panel on Climate Change (IPCC), Formula (1) was used to calculate the carbon emissions of the logistics industry in China's 30 provinces and regions:

$$
\mathrm{C}=\sum_{i} c_{i}=\sum_{i} \theta_{i} \times \beta_{i} \times E_{i}
$$

In the formula, $\mathrm{c}$ represents the total carbon emissions; $c_{i}$ is the carbon emissions of the i-th energy; $\theta_{i}$ is the carbon emission coefficient of the $\mathrm{i}$-th energy; $\beta_{i}$ is the conversion coefficient of the $i$-th energy; $E_{i}$ is the $\mathrm{i}$-th energy consumption. The conversion value stipulated in the "China Energy Statistics Yearbook" was adopted for $\beta_{\mathrm{i}}$, and the conversion coefficients used for various energy sources are shown in Table 1.

According to the IPCC estimation method, consumption data for eight types of energy including coal, coke, gasoline, kerosene, diesel, fuel oil, natural gas, and electricity are required. Energy consumption data used in this study were all derived from the China Energy Statistical Yearbook. The energy consumption data of similar fuels were based on the adjusted data of the China Energy Statistical Yearbook. GDP was derived from the China Statistical Yearbook and adjusted according to the constant price of the year to eliminate the impact of price fluctuations. The population data, including the arithmetic mean, was as at the end of the previous year and was taken from the China Statistical Yearbook. The category of "logistics industry" is not separately identified in existing statistical data. From the data of the "Statistical Yearbook of China's Tertiary Industry (2006)", the combination of transportation, warehousing, and postal industries accounts for more than $83 \%$ of the total logistics industry production value. Thus, this share, to a large extent, represents the development status of the logistics industry. In view of the availability of data, this study used the statistical data of the transportation, warehousing, and postal industries to represent the logistics industry, and determined the source of carbon emissions in the logistics industry as the direct source of the above industries. Consumption of eight types of energy were considered, namely raw coal, kerosene, diesel, gasoline, fuel oil, liquefied petroleum gas, natural gas, and electricity.

Table 1. Energy conversion factor to standard coal.

\begin{tabular}{|c|c|c|}
\hline Energy variety & $\begin{array}{c}\text { Conversion factor } \\
\text { of standard coal } \\
\text { (kg standard coal) }\end{array}$ & $\begin{array}{c}\text { Carbon emission } \\
\text { factor } \\
\text { (t carbon/tce) }\end{array}$ \\
\hline Coal $(\mathrm{kg})$ & 0.7143 & 0.7467 \\
\hline Diesel oil $(\mathrm{kg})$ & 1.4571 & 0.5913 \\
\hline Gasoline $(\mathrm{kg})$ & 1.4714 & 0.5532 \\
\hline Kerosene $(\mathrm{kg})$ & 1.4714 & 0.3416 \\
\hline Fuel oil $(\mathrm{kg})$ & 1.4286 & 0.6176 \\
\hline Coke $(\mathrm{kg})$ & 0.9714 & 0.1128 \\
\hline Electricity $(\mathrm{kw} \cdot \mathrm{h})$ & 0.1229 & 2.2132 \\
\hline Natural gas $\left(\mathrm{m}^{3}\right)$ & 1.3300 & 0.4479 \\
\hline
\end{tabular}




\section{Theil Index Method}

The Theil index is an index proposed by Dutch economist Henri Theil in 1967 using the concept of entropy in information theory to calculate income imbalances between individuals or between regions. The Theil index is spatially decomposable. The biggest advantage is that the overall difference can be subdivided into two parts: within-group differences and between-group differences, to observe and reveal differences in directions and magnitudes of changes within and between groups. The importance and influence of each contributor to the total difference can be assessed. The smaller the Theil index value, the smaller the regional difference; the larger the value, the greater the regional difference. The calculation formula of Theil index for carbon emissions is:

$$
\begin{gathered}
T_{B}=\sum_{j}\left(\frac{C_{j}}{C}\right) \ln \left(\frac{C_{j} / C}{G_{j} / G}\right) \\
T_{w i}=\sum_{j}\left(\frac{C_{j i}}{C_{j}}\right) \ln \left(\frac{C_{j i} / C_{j}}{G_{j i} / G_{j}}\right) \\
T_{W}=\sum_{j}\left(\frac{C_{j}}{C}\right) T_{w i}=\sum_{j} \sum_{i}\left(\frac{C_{j}}{C}\right)\left(\frac{C_{j i}}{C_{j}}\right) \ln \left(\frac{C_{j i} / C_{j}}{G_{j i} / G_{j}}\right) \\
\mathrm{T}=T_{B}+T_{W}=T_{B}+\sum_{j}\left(\frac{C_{j}}{C}\right) T_{w i}
\end{gathered}
$$

...where $\mathrm{j}$ is the region and $\mathrm{i}$ is the province. In Equation (2), $T_{B}$ is the inter-regional Theil index; in Equation (3), $T_{w i}$ is the Theil index in different regions within the region; in Equation (4), $\mathrm{T}_{\mathrm{w}}$ is the intra-region Theil index; in Equation (5), $\mathrm{T}$ is the overall difference in Theil index across provinces across the country. $\mathrm{C}$ and $\mathrm{G}$, respectively, represent the sum of national carbon emissions and GDP; $\mathrm{C}_{\mathrm{j}}$ and $\mathrm{G}_{\mathrm{j}}$, respectively, represent the sum of carbon emissions in each region and the sum of GDP in each region; $\mathrm{C}_{\mathrm{ji}}$ and $\mathrm{G}_{\mathrm{ji}}$, respectively, represent the carbon emissions and GDP of the i-th province in region $\mathrm{j}$.

\section{LMDI Decomposition Method}

From a macro perspective, the carbon emissions of the regional logistics industry are closely related to regional economic development and logistics and transportation demand. In addition, emissions are closely related to the choice of transportation, the energy consumption structure, the intensity of energy utilization, and the output effect of logistics. Among the many driving factors, some have a positive influence and correlation, while others inhibit the relationships of secondary drivers and have a negative correlation. Therefore, according to the index sub-model (LMDI), total carbon emissions of the regional logistics industry can be expressed by the following basic formula:

$$
C^{t}=\sum_{i j} \frac{C_{i j}^{t}}{E_{i j}^{t}} \times \frac{E_{i j}^{t}}{E_{j}^{t}} \times \frac{E_{j}^{t}}{T_{j}^{t}} \times \frac{T_{j}^{t}}{T^{t}} \times \frac{T^{t}}{Y^{t}} \times \frac{Y^{t}}{P^{t}} \times P^{t}
$$

...where $i$ represents the energy consumption type of the logistics industry; $\mathrm{j}$ represents the logistics transportation mode - this study focused on the relevant data of the three transportation modes of railway, highway, and water transportation; $\mathrm{t}$ represents the year; E represents the terminal energy consumption of the logistics industry; and $\mathrm{T}$ represents the logistics service. This study focused on the value added of the logistics industry, and $\mathrm{Y}$ was used as the indicator to measure economic output (i.e., GDP). P represents the demographic factor. Formula (6) can be further transformed into:

$$
C^{t}=E C_{i j}^{t} \times E S_{i j}^{t} \times E I_{j}^{t} \times T M_{j}^{t} \times T G^{t} \times Y G^{t} \times P^{t}
$$

...where $E C_{i j}{ }^{t}$ represents the carbon emission factor of the i-th energy in year t, $E S_{i j}{ }^{t}$ is the energy use structure of the regional logistics industry in year t, $E I_{j}^{t}$ represents the energy use intensity of the regional logistics industry in year $\mathrm{t}, T M_{j}^{t}$ represents the transport mode effect of the regional logistics industry in year t, $T G^{t}$ represents the output benefit of the regional logistics industry in year $\mathrm{t}, Y G^{t}$ represents the regional economic development level in year $\mathrm{t}$, and $P^{t}$ represents the area population in year t. According to the additive form of LMDI, the changes in energy consumption and carbon emissions of the regional logistics industry can be further decomposed into:

$$
\begin{gathered}
\Delta C_{t o t}=C^{t}-C^{0}=\Delta C_{E C}+\Delta C_{E S}+\Delta C_{E I}+\Delta C_{T M}+ \\
\Delta C_{T G}+\Delta C_{R G}+\Delta C_{P}
\end{gathered}
$$

where:

Carbon emission factor effect:

$$
\Delta C_{E C}=\sum_{i j} \omega_{i j} \ln \frac{E C_{i j}^{t}}{E C_{i j}^{0}}
$$

Energy structure effect:

$$
\Delta C_{E S}=\sum_{i j} \omega_{i j} \ln \frac{E S_{i j}^{t}}{E S_{i j}^{0}}
$$

Energy intensity effect:

$$
\Delta C_{E I}=\sum_{i j} \omega_{i j} \ln \frac{E I_{j}^{t}}{E I_{j}^{0}}
$$

Transport mode effect:

$$
\Delta C_{T M}=\sum_{i j} \omega_{i j} \ln \frac{T M_{j}^{t}}{T M_{j}^{0}}
$$

Logistics output effect:

$$
\Delta C_{T G}=\sum_{i j} \omega_{i j} \ln \frac{T G_{j}^{t}}{T G_{j}^{0}}
$$


Economic development effect:

$$
\Delta C_{Y G}=\sum_{i j} \omega_{i j} \ln \frac{Y G_{j}^{t}}{Y G^{0}}
$$

Population size effect:

$$
\Delta C_{P}=\sum_{i j} \omega_{i j} \ln \frac{P^{t}}{P^{0}}
$$

The multiplicative decomposition method can decompose the carbon emission changes of the logistics industry at the beginning and end of a period into the product of the contributions of the changes of various influencing factors, namely:

$$
D_{t o t}=\frac{C^{t}}{C^{0}}=D_{E C} \cdot D_{E S} \cdot D_{E I} \cdot D_{T M} \cdot D_{T G} \cdot D_{Y G} \cdot D_{P}
$$

where:

$$
\begin{gathered}
D_{E C}=\exp \left[\sum_{i j} \frac{\omega_{i j}}{\left(C^{t}-C^{o}\right) /\left(\ln C^{t}-\ln C^{0}\right)} \ln \frac{E C_{i j}^{t}}{E C_{i j}^{0}}\right] \\
D_{E S}=\exp \left[\sum_{i j} \frac{\omega_{i j}}{\left(C^{t}-C^{o}\right) /\left(\ln C^{t}-\ln C^{0}\right)} \ln \frac{E S_{i j}^{t}}{E S_{i j}^{0}}\right] \\
D_{E I}=\exp \left[\sum_{i j} \frac{\omega_{i j}}{\left(C^{t}-C^{o}\right) /\left(\ln C^{t}-\ln C^{0}\right)} \ln \frac{E I_{j}^{t}}{E I_{j}^{0}}\right] \\
D_{T M}=\exp \left[\sum_{i j} \frac{\omega_{i j}}{\left(C^{t}-C^{0}\right) /\left(\ln C^{t}-\ln C^{0}\right)} \ln \frac{T M_{j}^{t}}{T M_{j}^{0}}\right] \\
D_{T G}=\exp \left[\sum_{i j} \frac{\omega_{i j}}{\left(C^{t}-C^{o}\right) /\left(\ln C^{t}-\ln C^{0}\right)} \ln \frac{T G_{j}^{t}}{T G_{j}^{0}}\right] \\
D_{Y G}=\exp \left[\sum_{i j} \frac{\omega_{i j}}{\left(C^{t}-C^{o}\right) /\left(\ln C^{t}-\ln C^{0}\right)} \ln \frac{Y G^{t}}{Y G^{0}}\right] \\
D_{P}=\exp \left[\sum_{i j} \frac{\omega_{i j}}{\left(C^{t}-C^{0}\right) /\left(\ln C^{t}-\ln C^{0}\right)} \ln \frac{P^{t}}{P^{0}}\right]
\end{gathered}
$$

...where $t$ and 0 represent the end and the beginning of the period respectively, and the meaning of each indicator is shown in Table 2.

\section{Results and Discussion}

\section{Results of the Logistics Industry Carbon Emission in China's Three Major Regions}

Table 3 shows the evolution trend of the total carbon emissions of the logistics industry in China's three major regions. The large differences in the development level of the logistics industry across China inevitably lead to an imbalance in the total energy consumption and carbon emissions in each region. It can be seen from Table 3 that during the inspection period, the total carbon emissions of the logistics industry in the three major eastern, central, and western regions showed a significant upward trend. In terms of growth rates, that of total carbon emissions in the eastern region was significantly higher than that in the central and western regions. From the perspective of the absolute value of carbon emissions in various regions, the eastern region has the highest carbon emissions, followed by the central region, and the western region has the lowest. This result is generally consistent with the development level of the logistics industry in the various regions. From a national perspective, carbon emissions rose from 449.57 million tons in 2010 to 676.34 million tons in 2019 , a significant increase of $50.44 \%$. This also reflects the rapid development of China's logistics industry.

To facilitate the investigation of the composition of carbon emission sources in China's logistics industry, we divided the eight types of energy types into three categories, namely coal (raw coal), petroleum (crude oil, gasoline, kerosene, diesel, and fuel oil), natural gas (liquefied petroleum gas and natural gas). The energy consumption of China's logistics industry is shown in Table 4.

Table 4 shows the composition and proportion of carbon emission sources in China's logistics industry from 2010 to 2019. From Table 4, it can be concluded that the consumption of oil and natural gas in China's logistics industry also steadily increased, with oil consumption rising from 371.21 million tons in 2010 to 57,674 tons of standard coal in 2019 , an increase of $55.37 \%$. Furthermore, the proportion of oil consumption increased from $71 \%$ in 1995 to $86 \%$ in 2007 , and

Table 2. Meanings of various variable symbols.

\begin{tabular}{|c|c|c|c|}
\hline Variable & Meaning & Variable & Meaning \\
\hline $\mathrm{EC}$ & Carbon emission intensity factors & $\Delta \mathrm{C}_{\mathrm{EC}}, \mathrm{D}_{\mathrm{EC}}$ & The effect of carbon emission factors \\
\hline $\mathrm{ES}$ & Energy structure factors & $\Delta \mathrm{C}_{\mathrm{ES}}, \mathrm{D}_{\mathrm{ES}}$ & The influence of energy structure factors \\
\hline $\mathrm{EI}$ & Energy intensity factor & $\Delta \mathrm{C}_{\mathrm{EI}}, \mathrm{D}_{\mathrm{EI}}$ & The impact of energy intensity factors \\
\hline $\mathrm{TM}$ & Logistics transportation method & $\Delta \mathrm{C}_{\mathrm{TM}}, \mathrm{D}_{\mathrm{TM}}$ & The effect of logistics transportation \\
\hline $\mathrm{TG}$ & Logistics industry development factors & $\Delta \mathrm{C}_{\mathrm{TG}}, \mathrm{D}_{\mathrm{TG}}$ & The influence effect of logistics industry development factors \\
\hline $\mathrm{YG}$ & Economic development factors & $\Delta \mathrm{C}_{\mathrm{YG}}, \mathrm{D}_{\mathrm{YG}}$ & The influence of economic development factors \\
\hline $\mathrm{P}$ & Demographic factors & $\Delta \mathrm{C}_{\mathrm{P}}, \mathrm{D}_{\mathrm{P}}$ & Demographic effect \\
\hline
\end{tabular}


Table 3. Total carbon emissions in China and each region.

\begin{tabular}{|c|c|c|c|c|c|c|c|c|c|c|}
\hline & 2010 & 2011 & 2012 & 2013 & 2014 & 2015 & 2016 & 2017 & 2018 & 2019 \\
\hline Eastern Region & 2.2293 & 2.2858 & 2.3109 & 2.3345 & 2.3866 & 2.4533 & 2.5743 & 2.6931 & 2.8876 & 3.1298 \\
\hline Central Region & 1.2922 & 1.3096 & 1.3344 & 1.3539 & 1.3998 & 1.4742 & 1.7463 & 2.1072 & 2.2332 & 2.3122 \\
\hline Western Region & 0.9742 & 1.1217 & 1.1267 & 1.1288 & 1.1311 & 1.1377 & 1.2135 & 1.2457 & 1.2909 & 1.3214 \\
\hline National & 4.4957 & 4.7171 & 4.772 & 4.8172 & 4.9175 & 5.0652 & 5.5341 & 6.046 & 6.4117 & 6.7634 \\
\hline
\end{tabular}

then declined to $82.57 \%$ in 2012 . The average over the entire period was $85 \%$. It can be seen that oil still plays a significant role in the logistics industry. Natural gas consumption grew rapidly, from 164.5 million tons of standard coal in 2010 to 74.88 million tons of standard coal in 2019, an increase of $355.20 \%$, and the proportion of natural gas consumption also increased, from $3.66 \%$ in 2010 to $11.07 \%$ in 2019 . This rapid growth shows that China is determined to implement low-carbon logistics. However, coal consumption in the logistics industry declined, from 0.6191 million tons of standard coal in 2010 to 24.72 million tons of standard coal in 2019, a decrease of $60.07 \%$; and the proportion of coal consumption also fell, from $13.77 \%$ to $3.66 \%$. From the above analysis, it can be seen that the shift of the energy consumption structure of China's logistics industry from coal to oil and natural gas helped reduce the carbon emissions of the logistics industry.

\section{The Theil Index Calculation Results in China and Various Regions}

Following the measurement and analysis of carbon emissions in the logistics industry across China and the three major regions, we calculated the Theil index values of carbon emissions from 2010 to 2019, as shown in Table 5. It can be seen from Table 5 that during the study period, the highest value of the overall Theil index of the carbon emissions of China's logistics industry was 0.3112 in 2011, the lowest value was 0.2661 in 2010, and the average value was 0.2808 . Overall, the interprovincial difference in carbon emissions of China's logistics industry did not change substantially, and showed a downward trend. Within the study period, the overall Theil index of the logistics industry's carbon emissions fluctuated significantly from 2010 to 2012, and the range of changes from 2013 to 2015 was relatively large. Thereafter, the overall index was relatively stable, with a downward trend. The change trend of the Theil index in the regions was similar to that of the overall Theil index, with an average value of 0.2553 . The inter-regional Theil index value was lower than the intra-regional Theil index value, with an average value of 0.0345 , and showed a slow upward trend overall. From the perspective of the Theil index of the three major regions, the eastern region had the highest Theil index value, with an average value of 0.2959 , and the central region was slightly lower, with an average value of 0.2921 . From 2010 to 2015, the eastern region's Theil index value was lower than that of the central region. After 2016, the Theil index value of the eastern region was greater than that of the central region, indicating that the difference in carbon emissions between the eastern and central regions began to expand after 2015. The Theil index value of the western region during the study period was lower than those of the eastern and central regions, and the range of changes was small. The maximum value was 0.0921 in 2010, the minimum value was 0.0497 in 2016, and the average value was 0.0619 .

It can be seen from Table 5 that during the study period the average contribution rate of the Theil index within the regions was $88 \%$, which was significantly higher than the $12 \%$ contribution rate of the inter-regional Theil index. From the perspective of evolutionary trends, after the inter-regional Theil index contribution rate declined in 2010, it showed a rising trend from 2012. The change trend of the regional Theil index contribution rate was in line with the inter-regional Theil index contribution rate. In general, the regional differences in carbon emissions of China's logistics industry have maintained a continuous downward trend, and the total contribution rate of carbon emissions from the logistics industry among the three regions is higher than the regional differences.

Table 4. Composition and proportion of carbon emission sources in China's logistics industry from 2010 to 2019.

\begin{tabular}{|c|c|c|c|c|c|c|c|c|c|c|}
\hline & 2010 & 2011 & 2012 & 2013 & 2014 & 2015 & 2016 & 2017 & 2018 & 2019 \\
\hline \multirow{2}{*}{ Coal } & $\begin{array}{c}0.6191 \\
(13.77 \%)\end{array}$ & $\begin{array}{c}0.6288 \\
(13.33 \%)\end{array}$ & $\begin{array}{c}0.5899 \\
(12.36 \%)\end{array}$ & $\begin{array}{c}0.4501 \\
(9.34 \%)\end{array}$ & $\begin{array}{c}0.3576 \\
(7.28 \%)\end{array}$ & $\begin{array}{c}0.3023 \\
(5.97 \%)\end{array}$ & $\begin{array}{c}0.2818 \\
(5.09 \%)\end{array}$ & $\begin{array}{c}0.2721 \\
(4.50 \%)\end{array}$ & $\begin{array}{c}0.2632 \\
(4.11 \%)\end{array}$ & $\begin{array}{c}0.2472 \\
(3.66 \%)\end{array}$ \\
\hline \multirow{2}{*}{ Petro } & $\begin{array}{c}3.7121 \\
(82.57 \%)\end{array}$ & $\begin{array}{c}3.8812 \\
(82.28 \%)\end{array}$ & $\begin{array}{c}3.9639 \\
(83.07 \%)\end{array}$ & $\begin{array}{c}4.1192 \\
(85.51 \%)\end{array}$ & $\begin{array}{c}4.2699 \\
(86.83 \%)\end{array}$ & $\begin{array}{c}4.3798 \\
(86.47 \%)\end{array}$ & $\begin{array}{c}4.7349 \\
(85.56 \%)\end{array}$ & $\begin{array}{c}5.1753 \\
(85.603 \%)\end{array}$ & $\begin{array}{c}5.4482 \\
(84.97 \%)\end{array}$ & $\begin{array}{c}5.7674 \\
(85.27 \%)\end{array}$ \\
\hline \multirow{2}{*}{ Natural gas } & $\begin{array}{c}(8.1645 \\
(3.66 \%)\end{array}$ & $\begin{array}{c}0.2071 \\
(4.39 \%)\end{array}$ & $\begin{array}{c}0.2182 \\
(4.57 \%)\end{array}$ & $\begin{array}{c}0.2479 \\
(5.15 \%)\end{array}$ & $\begin{array}{c}0.29 \\
(5.89 \%)\end{array}$ & $\begin{array}{c}0.3831 \\
(7.56 \%)\end{array}$ & $\begin{array}{c}0.5174 \\
(9.35 \%)\end{array}$ & $\begin{array}{c}0.5986 \\
(9.90 \%)\end{array}$ & $\begin{array}{c}0.7003 \\
(10.92 \%)\end{array}$ & $\begin{array}{c}0.7488 \\
(11.07 \%)\end{array}$ \\
\hline
\end{tabular}


Table 5. Theil index calculation results for China and each region.

\begin{tabular}{|c|c|c|c|c|c|c|c|c|}
\hline Year & National & Eastern & Central & Western & Tw & Tb & $\begin{array}{c}\text { Tw } \\
\text { Contribution rate \% }\end{array}$ & $\begin{array}{c}\text { Tb } \\
\text { Contribution rate \% }\end{array}$ \\
\hline 2010 & 0.3023 & 0.2978 & 0.3419 & 0.0921 & 0.2833 & 0.0435 & 0.8669 & 0.1331 \\
\hline 2011 & 0.3112 & 0.3102 & 0.3598 & 0.0833 & 0.2901 & 0.0432 & 0.8704 & 0.1296 \\
\hline 2012 & 0.3019 & 0.3022 & 0.3512 & 0.0733 & 0.2744 & 0.0334 & 0.8915 & 0.1085 \\
\hline 2013 & 0.2823 & 0.2974 & 0.3322 & 0.0534 & 0.2634 & 0.0324 & 0.8905 & 0.1095 \\
\hline 2014 & 0.2766 & 0.2877 & 0.3124 & 0.0519 & 0.2549 & 0.0299 & 0.8950 & 0.1050 \\
\hline 2015 & 0.2691 & 0.2933 & 0.3048 & 0.0502 & 0.2498 & 0.0282 & 0.8986 & 0.1014 \\
\hline 2016 & 0.2432 & 0.3012 & 0.2877 & 0.0478 & 0.2412 & 0.0274 & 0.8980 & 0.1020 \\
\hline 2017 & 0.2334 & 0.2913 & 0.2865 & 0.0514 & 0.2339 & 0.0243 & 0.9059 & 0.0941 \\
\hline 2018 & 0.2209 & 0.2901 & 0.2581 & 0.0522 & 0.2319 & 0.0231 & 0.9094 & 0.0906 \\
\hline 2019 & 0.2091 & 0.2876 & 0.2342 & 0.0629 & 0.2298 & 0.0211 & 0.9159 & 0.0841 \\
\hline Mean & 0.2650 & 0.2959 & 0.3069 & 0.0619 & 0.2553 & 0.0307 & 0.8942 & 0.1058 \\
\hline
\end{tabular}

Decomposition Results of Factors Affecting Carbon Emissions of China's Logistics Industry

\section{Decomposition Results of Factors Affecting Carbon Emissions of China's Logistics Industry}

In the LMDI decomposition model of the influencing factors of the logistics industry's carbon emissions used in this study, the 2010-2019 base periods was used to decompose the factors affecting the changes in the national logistics industry's energy consumption and carbon emissions. The results are shown in Table 6.

It can be seen that the overall effect of various influencing factors on changes in carbon emissions shows an overall upward trend, and only declined in 2018, further verifying that the LMDI decomposition model is robust. Overall, economic development is the most important factor that promoted the increase of carbon emissions in China's logistics industry. The contribution rate of transportation methods, energy intensity factors, and energy structure factors were the next most important factors. The contribution rate of population was the smallest factor. Only logistics output exerted a restraint on the logistics industry. The role of carbon emissions and the intensity of that role increased.

Economic development effects. Economic growth is the main driver of the increase in China's carbon emissions. This conclusion is consistent with the findings of most scholars [37]. At the national level, China's logistics industry experienced a stage of relatively rapid carbon emission growth; the logistics industry's carbon emissions increased by 420 million tons between 2003 and 2016. The LMDI decomposition

Table 6. Decomposition of factors affecting carbon emissions in China's logistics industry.

\begin{tabular}{|c|c|c|c|c|c|c|c|c|c|c|c|c|c|c|}
\hline \multirow{2}{*}{ Year } & \multicolumn{2}{|c|}{$\begin{array}{l}\text { Energy } \\
\text { intensity }\end{array}$} & \multicolumn{2}{|c|}{$\begin{array}{l}\text { Energy } \\
\text { structure }\end{array}$} & \multicolumn{2}{|c|}{$\begin{array}{c}\text { Mode } \\
\text { of transport }\end{array}$} & \multicolumn{2}{|c|}{$\begin{array}{c}\text { Logistics } \\
\text { development }\end{array}$} & \multicolumn{2}{|c|}{$\begin{array}{l}\text { Economic } \\
\text { Growth }\end{array}$} & \multicolumn{2}{|c|}{$\begin{array}{l}\text { Population } \\
\text { size }\end{array}$} & \multicolumn{2}{|c|}{ Total effect } \\
\hline & $\mathrm{D}_{\mathrm{EI}}$ & $\Delta \mathrm{C}_{\mathrm{E}}$ & $\mathrm{D}_{\mathrm{ES}}$ & $\Delta \mathrm{C}_{\mathrm{ES}}$ & $\mathrm{D}_{\mathrm{TM}}$ & $\Delta \mathrm{C}_{\mathrm{TM}}$ & $\mathrm{D}_{\mathrm{TG}}$ & $\Delta \mathrm{C}_{\mathrm{TG}}$ & $\mathrm{D}_{\mathrm{YG}}$ & $\Delta \mathrm{C}_{\mathrm{YG}}$ & $\mathrm{D}_{\mathrm{P}}$ & $\Delta \mathrm{C}_{\mathrm{P}}$ & $\mathrm{D}_{\text {tot }}$ & $\Delta \mathrm{C}_{\mathrm{tot}}$ \\
\hline 2010 & 1.001 & 112 & 0.923 & 8 & 1.012 & 0 & 0.982 & -22 & 1.124 & 567 & 0.993 & -4 & 1.117 & 334 \\
\hline 2011 & 1.009 & 1134 & 0.946 & 34 & 0.981 & 9 & 0.903 & -454 & 1.331 & 3242 & 1.001 & -66 & 1.298 & 1346 \\
\hline 2012 & 1.012 & 1456 & 0.953 & 57 & 0.984 & 15 & 0.865 & -587 & 1.432 & 4453 & 1.009 & -134 & 1.494 & 2677 \\
\hline 2013 & 1.023 & 1123 & 0.966 & 89 & 0.993 & 33 & 0.854 & -1123 & 1.675 & 6782 & 1.014 & -178 & 1.673 & 5612 \\
\hline 2014 & 1.028 & -443 & 1.004 & 145 & 1.013 & 76 & 0.899 & -1467 & 1.889 & 9878 & 1.021 & -234 & 1.892 & 6565 \\
\hline 2015 & 1.035 & -488 & 1.013 & 167 & 1.063 & 98 & 0.903 & -1768 & 1.921 & 10245 & 1.033 & -278 & 1.972 & 7823 \\
\hline 2016 & 1.047 & -889 & 1.093 & 456 & 1.095 & 112 & 0.891 & -1876 & 2.249 & 11456 & 1.031 & -332 & 2.325 & 9045 \\
\hline 2017 & 1.054 & -765 & 1.112 & 487 & 1.116 & 145 & 0.884 & -2034 & 2.188 & 12671 & 1.035 & -347 & 2.349 & 10568 \\
\hline 2018 & 1.069 & -654 & 1.098 & 365 & 1.129 & 236 & 0.875 & -1989 & 2.199 & 12458 & 1.043 & -377 & 2.282 & 10123 \\
\hline 2019 & 1.072 & -459 & 1.084 & 323 & 1.142 & 287 & 0.862 & -1700 & 2.205 & 11238 & 1.052 & -247 & 2.561 & 10224 \\
\hline
\end{tabular}


results in Table 6 show that GDP per capita has a strong influence on the growth of the carbon emissions of the logistics industry. This conclusion is also consistent with those of other researchers [38-39]. Moreover, there is a positive effect between the growth of per capita GDP and the carbon emissions of the logistics industry. Due to the improvement of the economic level, demand for products is higher and the use of logistics increases rapidly, thereby increasing the industry's carbon emissions. Further analysis shows that the most significant period for per capita GDP was 2010-2013. The economic development effect exceeded the total effect, mainly because China's economy grew rapidly during this period, but relied largely on high investment and high consumption. Economic growth has higher environmental costs.

Logistics output effect. From a national perspective, China's logistics output has a negative effect on the growth of carbon emissions in the logistics industry. This conclusion is consistent with Wang and Liu [40], Zeng and Zhou [2] and other related scholars. This conclusion shows that the output effect of China's logistics industry has a restraining effect on the industry's carbon emissions, and the intensity of the effect has a fluctuating growth trend. Due to the development of science and technology, the logistics industry has undergone constant modernization. As a result, the energy efficiency of logistics has improved, and the logistics output effect is negative.

Energy structure effect. The energy structure effect can be divided into two stages: The energy structure effect from 2004 to 2007 showed a weak negative effect. During this period, the proportion of coal consumption continued to decrease, thus restraining carbon emissions. However, since 2008, the proportion of coal consumption has gradually decreased, and the inhibitory effect also gradually decreased. The continuous increase in petroleum energy consumption played a role in the increase in carbon emissions, which is consistent with the research of scholar Wang (2019) [41]. Since 2013, the positive effect of the energy structure has gradually weakened, indicating that the energy consumption structure of China's logistics industry has improved, but substantial room remains for structural optimization.

Energy intensity effect. The energy intensity effect has a positive influence on carbon emissions. Further analysis shows that the energy intensity effect is mainly divided into three stages: In 2004-2008 the effect gradually increased, mainly because of the continuous increase in the energy intensity of China's logistics industry during this period. In 2009-2012, the effect gradually weakened because the energy intensity of China's logistics industry began to decline in 2008. This effect reached its peak in 2013 and then slowly declined, most likely because of China's promotion of new energy. Overall, however, the contribution rate of energy intensity to the change in carbon emissions of the logistics industry was relatively small.

The effect of transportation mode. During the study period, the freight turnover of rail transport accounted for $33.96 \%$ of total freight turnover in 2004 and dropped to $14.05 \%$ in 2016 , while the ratio of public transport cargo turnover to total cargo turnover rose from $14.68 \%$ in 2004 to $36.83 \%$ in 2016 . Water transport is typically the dominant mode in China due to its relatively low cost. As a result, the proportion of water transportation has changed relatively little during the study period, and is divided into two stages. The proportion of water transportation showed an upward trend during 2004-2008 before declining in 2009-2016. Therefore, the impact of transportation methods on the carbon emissions of the logistics industry mainly depended on public transportation and rail transportation.

Table 7. Decomposition results of factors affecting carbon emissions of logistics industry in the eastern region.

\begin{tabular}{|c|c|c|c|c|c|c|c|c|c|c|c|c|c|c|}
\hline \multirow[t]{2}{*}{ Year } & \multicolumn{2}{|c|}{$\begin{array}{c}\text { Energy } \\
\text { intensity }\end{array}$} & \multicolumn{2}{|c|}{$\begin{array}{c}\text { Energy } \\
\text { structure }\end{array}$} & \multicolumn{2}{|c|}{$\begin{array}{c}\text { Mode } \\
\text { of transport }\end{array}$} & \multicolumn{2}{|c|}{$\begin{array}{l}\text { Logistics devel- } \\
\text { opment }\end{array}$} & \multicolumn{2}{|c|}{$\begin{array}{l}\text { Economic } \\
\text { Growth }\end{array}$} & \multicolumn{2}{|c|}{$\begin{array}{l}\text { Population } \\
\text { size }\end{array}$} & \multicolumn{2}{|c|}{$\begin{array}{l}\text { Total } \\
\text { effect }\end{array}$} \\
\hline & $\mathrm{D}_{\mathrm{EI}}$ & $\Delta \mathrm{C}_{\mathrm{E}}$ & $\mathrm{D}_{\mathrm{ES}}$ & $\Delta \mathrm{C}_{\mathrm{ES}}$ & $\mathrm{D}_{\mathrm{TM}}$ & $\Delta \mathrm{C}_{\mathrm{TM}}$ & $\mathrm{D}_{\mathrm{TG}}$ & $\Delta \mathrm{C}_{\mathrm{TG}}$ & $\mathrm{D}_{\mathrm{YG}}$ & $\Delta \mathrm{C}_{\mathrm{YG}}$ & $\mathrm{D}_{\mathrm{P}}$ & $\Delta \mathrm{C}_{\mathrm{P}}$ & $\mathrm{D}_{\text {tot }}$ & $\Delta \mathrm{C}_{\text {tot }}$ \\
\hline 2010 & 1.012 & 453 & 1.010 & 33 & 1.001 & 87 & 1.002 & 65 & 1.164 & 1562 & 1.002 & 77 & 1.217 & 2277 \\
\hline 2011 & 1.056 & 786 & 1.026 & 123 & 1.012 & 156 & 1.012 & 87 & 1.151 & 5213 & 1.021 & 365 & 1.498 & 6730 \\
\hline 2012 & 1.073 & 935 & 1.003 & 235 & 1.010 & 168 & 1.023 & 331 & 1.654 & 6413 & 1.038 & 476 & 1.691 & 8558 \\
\hline 2013 & 1.069 & 1011 & 1.006 & 281 & 1.005 & 132 & 0.998 & -1543 & 1.988 & 9897 & 1.067 & 987 & 1.977 & 10765 \\
\hline 2014 & 1.046 & 1345 & 0.995 & -241 & 0.898 & -776 & 0.889 & -2346 & 2.482 & 12812 & 1.099 & 1267 & 2.192 & 12061 \\
\hline 2015 & 0.988 & -756 & 0.989 & -335 & 0.892 & -991 & 0.842 & -3489 & 2.909 & 14654 & 1.108 & 1435 & 2.276 & 10518 \\
\hline 2016 & 0.961 & -1231 & 0.993 & -487 & 0.883 & -1922 & 0.813 & -4776 & 3.149 & 18921 & 1.111 & 1653 & 2.325 & 12158 \\
\hline 2017 & 0.889 & -2234 & 0.984 & -576 & 0.876 & -2445 & 0.783 & -5438 & 3.764 & 22547 & 1.155 & 2666 & 2.413 & 14520 \\
\hline 2018 & 0.901 & -3688 & 0.098 & -412 & 0.892 & -2132 & 0.775 & -4589 & 3.591 & 21358 & 1.143 & 2568 & 2.582 & 13105 \\
\hline 2019 & 0.913 & -2451 & 0.987 & -388 & 0.898 & -2033 & 0.752 & -4500 & 3.992 & 25231 & 1.152 & 2788 & 2.762 & 18647 \\
\hline
\end{tabular}


Table 8. Decomposition results of factors affecting carbon emissions of the logistics industry in the central region.

\begin{tabular}{|c|c|c|c|c|c|c|c|c|c|c|c|c|c|c|}
\hline \multirow{2}{*}{ Year } & \multicolumn{2}{|c|}{$\begin{array}{l}\text { Energy } \\
\text { intensity }\end{array}$} & \multicolumn{2}{|c|}{$\begin{array}{c}\text { Energy } \\
\text { structure }\end{array}$} & \multicolumn{2}{|c|}{$\begin{array}{c}\text { Mode } \\
\text { of transport }\end{array}$} & \multicolumn{2}{|c|}{$\begin{array}{c}\text { Logistics devel- } \\
\text { opment }\end{array}$} & \multicolumn{2}{|c|}{$\begin{array}{l}\text { Economic } \\
\text { Growth }\end{array}$} & \multicolumn{2}{|c|}{$\begin{array}{c}\text { Population } \\
\text { size }\end{array}$} & \multicolumn{2}{|c|}{$\begin{array}{l}\text { Total } \\
\text { effect }\end{array}$} \\
\hline & $\mathrm{D}_{\mathrm{EI}}$ & $\Delta \mathrm{C}_{\mathrm{E}}$ & $\mathrm{D}_{\mathrm{ES}}$ & $\Delta \mathrm{C}_{\mathrm{ES}}$ & $\mathrm{D}_{\mathrm{TM}}$ & $\Delta \mathrm{C}_{\mathrm{TM}}$ & $\mathrm{D}_{\mathrm{TG}}$ & $\Delta \mathrm{C}_{\mathrm{TG}}$ & $\mathrm{D}_{\mathrm{YG}}$ & $\Delta \mathrm{C}_{\mathrm{YG}}$ & $\mathrm{D}_{\mathrm{P}}$ & $\Delta \mathrm{C}_{\mathrm{P}}$ & $\mathrm{D}_{\text {tot }}$ & $\Delta \mathrm{C}_{\text {tot }}$ \\
\hline 2010 & 1.054 & 123 & 1.001 & 11 & 1.004 & 34 & 0.837 & -765 & 1.261 & 1678 & 0.964 & -71 & 1.307 & 1010 \\
\hline 2011 & 1.035 & 334 & 1.003 & 15 & 1.006 & 44 & 0.855 & -887 & 1.356 & 2132 & 0.972 & -65 & 1.343 & 1573 \\
\hline 2012 & 1.052 & 276 & 1.004 & 46 & 1.010 & 57 & 0.847 & -1333 & 1.677 & 3411 & 0.984 & -46 & 1.493 & 2411 \\
\hline 2013 & 0.956 & 239 & 1.012 & 135 & 1.025 & 131 & 0.798 & -1555 & 1.912 & 4237 & 0.994 & -37 & 1.673 & 3150 \\
\hline 2014 & 0.945 & 244 & 1.023 & 235 & 1.034 & 165 & 0.829 & -1546 & 2.333 & 5813 & 0.999 & -12 & 1.792 & 4899 \\
\hline 2015 & 0.934 & -445 & 1.035 & 341 & 1.042 & 223 & 0.742 & -1865 & 2.419 & 7654 & 1.004 & -5 & 2.136 & 5903 \\
\hline 2016 & 0.912 & -657 & 1.047 & 478 & 1.050 & 276 & 0.733 & -2172 & 3.244 & 7923 & 1.007 & 53 & 2.338 & 5901 \\
\hline 2017 & 0.924 & -864 & 1.024 & 587 & 1.055 & 332 & 0.688 & -2231 & 3.465 & 8549 & 1.011 & 66 & 2.445 & 6439 \\
\hline 2018 & 0.927 & -445 & 1.011 & 628 & 1.062 & 346 & 0.712 & -2433 & 3.391 & 9357 & 1.013 & 88 & 2.518 & 7541 \\
\hline 2019 & 0.941 & -423 & 1.007 & 668 & 1.068 & 478 & 0.734 & -2515 & 3.492 & 10234 & 1.016 & 148 & 2.844 & 8590 \\
\hline
\end{tabular}

The continuous expansion of public transport has a positive effect on the change of carbon emissions in the logistics industry, which is consistent with the research of scholar Liu Yu (2018) [42].

Population scale effect. The population scale factor has the smallest impact on the carbon emissions of the logistics industry, and contributed a small promotion.

\section{Decomposition Results of Factors Affecting Carbon Emissions of the Logistics Industry in China}

To further analyze the differences in the factors affecting the carbon emissions of the logistics industry in different regions, the factors in the three major regions were decomposed. Results are shown in Table 7, Table 8, and Table 9.
Based on the decomposition results of the influencing factors of the carbon emissions of regional logistics industries, analysis of the effects of the influencing factors in the three regions shows the following:

Energy intensity effect. The energy intensity effect showed substantial volatility, with its effect changing from initially positive to negative, and the most significant performance recorded in the eastern region. The energy intensity of the logistics industry in the three major regions had two inflection points in 2013 and 2016. The first inflection point was affected by the economic downturn in 2013, and the output value of the logistics industry fell sharply; the second inflection point was caused by the implementation of "Nine Logistics Countries", which enhanced the energy intensity suppression effect. The energy intensity effect fluctuated the most in the eastern region. The intensity

Table 9. Decomposition results of influencing factors of carbon emission in western logistics industry.

\begin{tabular}{|c|c|c|c|c|c|c|c|c|c|c|c|c|c|c|}
\hline \multirow[t]{2}{*}{ Year } & \multicolumn{2}{|c|}{$\begin{array}{l}\text { Energy } \\
\text { intensity }\end{array}$} & \multicolumn{2}{|c|}{$\begin{array}{l}\text { Energy } \\
\text { structure }\end{array}$} & \multicolumn{2}{|c|}{$\begin{array}{c}\text { Mode } \\
\text { of transport }\end{array}$} & \multicolumn{2}{|c|}{$\begin{array}{c}\text { Logistics devel- } \\
\text { opment }\end{array}$} & \multicolumn{2}{|c|}{$\begin{array}{l}\text { Economic } \\
\text { Growth }\end{array}$} & \multicolumn{2}{|c|}{ Population size } & \multicolumn{2}{|c|}{$\begin{array}{l}\text { Total } \\
\text { effect }\end{array}$} \\
\hline & $\mathrm{D}_{\mathrm{EI}}$ & $\Delta \mathrm{C}_{\mathrm{E}}$ & $\mathrm{D}_{\mathrm{ES}}$ & $\Delta \mathrm{C}_{\mathrm{ES}}$ & $\mathrm{D}_{\mathrm{TM}}$ & $\Delta \mathrm{C}_{\mathrm{TM}}$ & $\mathrm{D}_{\mathrm{TG}}$ & $\Delta \mathrm{C}_{\mathrm{TG}}$ & $\mathrm{D}_{\mathrm{YG}}$ & $\Delta \mathrm{C}_{\mathrm{YG}}$ & $\mathrm{D}_{\mathrm{P}}$ & $\Delta \mathrm{C}_{\mathrm{P}}$ & $\mathrm{D}_{\text {tot }}$ & $\mathrm{VC}_{\text {tot }}$ \\
\hline 2010 & 1.021 & 117 & 1.001 & 4 & 1.001 & 4 & 0.991 & -61 & 1.064 & 778 & 0.998 & -79 & 1.036 & 763 \\
\hline 2011 & 1.136 & 1217 & 1.002 & 19 & 1.002 & 15 & 0.983 & -87 & 1.254 & 3213 & 0.982 & -165 & 1.335 & 4212 \\
\hline 2012 & 1.204 & 1468 & 1.007 & 23 & 1.007 & 54 & 0.973 & -241 & 1.351 & 4414 & 0.974 & -176 & 1.547 & 5542 \\
\hline 2013 & 1.163 & 1034 & 1.016 & 81 & 1.011 & 78 & 0.934 & -343 & 1.623 & 6893 & 0.967 & -287 & 1.771 & 7456 \\
\hline 2014 & 1.045 & -345 & 1.021 & 141 & 1.018 & 145 & 0.881 & -642 & 2.581 & 7511 & 0.956 & -366 & 2.118 & 6444 \\
\hline 2015 & 0.983 & -456 & 1.036 & 135 & 1.021 & 223 & 0.856 & -889 & 2.801 & 8666 & 0.951 & -435 & 2.245 & 7244 \\
\hline 2016 & 0.973 & -1254 & 1.045 & 287 & 1.022 & 257 & 0.824 & -976 & 3.556 & 8921 & 0.962 & -653 & 2.525 & 6582 \\
\hline 2017 & 0.881 & -1534 & 1.036 & 373 & 1.027 & 334 & 0.781 & -1138 & 3.961 & 9542 & 0.965 & -767 & 2.718 & 6810 \\
\hline 2018 & 0.917 & -1121 & 1.048 & 415 & 1.035 & 376 & 0.803 & -1589 & 3.892 & 10355 & 0.968 & -568 & 2.981 & 7868 \\
\hline 2019 & 0.921 & -951 & 1.057 & 588 & 1.048 & 477 & 0.822 & -2312 & 3.797 & 12231 & 0.979 & -443 & 3.164 & 9590 \\
\hline
\end{tabular}


effect dropped sharply in 2015 and has been negative since then. After 2018, the effect level in the eastern region was lower than that in the central and western regions. The eastern region has a relatively high degree of urbanization, and the rapid promotion of carbon emission reduction technologies has effectively played a restraining role. However, the logistics industry in the central and western regions lags behind that of the eastern regions, the penetration rate of emission reduction technologies is not high and their impact is small; thus, the suppression of carbon emissions is limited.

Population size effect. The population size effect of the eastern region was positive, and the population size of the eastern region had a greater impact on the carbon emissions of the logistics industry. This is mainly because the population of the eastern region is larger than that of the central and western regions. The population scale effect in the central region changed from negative to positive. This is because the population of the central region continued to decrease from 2010 to 2015. Since 2015, the population of the central region has increased slowly, hence having a positive effect on logistics carbon emissions. The population of the western region exerted an inhibitory effect; however, the intensity of this effect was extremely small, mainly because the population of the western region flows to the east and central regions, causing the population of the western region to slowly shrink, thereby suppressing carbon emissions.

Energy structure effect. The effect of the energy structure in the eastern region changed from positive to negative. This is mainly due to the optimized energy consumption structure and cleaner energy consumption in the eastern region. In the central region, the energy structure contributed a weak positive effect, and the overall trend was to increase first and then decrease; however, the overall fluctuation was relatively small, mainly because the industrial structure of the central region was relatively stable, and the impact on carbon emissions was relatively small. The energy structure of the western region had a small promotional effect on the carbon emissions of the logistics industry, mainly because coal and diesel were the dominant factors in the energy structure effect. The logistics industry is highly dependent on diesel, kerosene, and other petroleum fuels.

Economic development effect. The effect of economic development is the most important positive effect, and it had a larger impact on the eastern and western regions than the central region. The economic development effects of the three major regions of China are generally positive and the most important. This conclusion is consistent with the previous research conclusions. Economic development factors in the eastern region have the greatest impact on the changes in the logistics industry, and have a positive effect on the industry's carbon emissions. Furthermore, the overall contribution rate showed an increasing trend.
Because of economic improvement, demand for a higher quality of life brought about by fast logistics methods has significantly increased freight turnover. The economic development factor in the central region also made the largest contribution to the total effect, and the contribution rate to the carbon emissions of the logistics industry was the largest among the major regions. The economic development of the western region had a significantly greater promotion of carbon emissions from the logistics industry than from other factors, and the effect of economic development showed a continuously increasing trend. It can be concluded that the western region has a relatively extensive economic development method and higher environmental costs.

Logistics industry development. The logistics industry in the eastern region is highly developed, its industry operates on a large scale, and the demand for primary energy is strong. In addition, the development of the logistics industry in the western region is oriented towards energy dependency. These factors led to higher economic development effects in the eastern and western regions. The logistics output effect had a negative effect in most years, but exhibited a small positive effect in 2010-2012. In 2013-2017, the negative effect increased slowly, before increasing more rapidly in 2018-2019. The reason for this phenomenon is that the "Twelfth Five-Year Plan" emphasized the realization of "the goal of reducing carbon emissions per unit of GDP by $17 \%$ ", which caused various regions to attach importance to the development of low-carbon green logistics industries. This led to the inhibition of carbon emissions. The logistics output effect in the central region was negative and, compared with other regions; it made a greater contribution to the change in the carbon emissions of the logistics industry. This is largely because the logistics industry's added value in the central region accounted for a greater proportion of regional GDP from 2010 to 2019, when the decline was greater.

Mode of transportation. The transportation mode in the eastern region had an inhibitory effect on the changes in the carbon emissions of the logistics industry. This is mainly because the proportion of water transportation in the eastern region gradually decreased from 2010 to 2019, while the proportion of rail transportation gradually increased, and the overall proportion of water transportation increased from 2010. The proportion of water transportation fell from $22.76 \%$ in 2010 to $4.32 \%$ in 2019 , and the proportion of rail transport increased from $4.58 \%$ in 2010 to $33.09 \%$ in 2019 , indicating that the eastern region's transportation methods were continuously optimized. The contribution rate of transportation methods to the changes in carbon emissions of the logistics industry was still relatively small, and showed a weak positive effect. The transportation mode in the western region also had a small positive effect on the carbon emissions of the logistics industry. 


\section{Conclusions}

Based on the energy consumption data of the logistics industry in 30 provinces and cities in China, this study used the carbon emission accounting method of the IPCC to estimate the total carbon emissions of the logistics industry in each province and city from 2010 to 2019. In addition, it also used the carbon emission Theil index and LMDI model to measure the regional differences in carbon emissions of China's logistics industry and decompose the influencing factors. The conclusions are as follows:

First, the scale of carbon emissions in the logistics industry and the industry's output value showed increasing trends from 2010 to 2019. However, the carbon emission reduction capabilities of various regions vary greatly. The eastern region achieved its initial results by strengthening emission reduction efforts to reduce carbon emissions. Compared with the central and western regions, the eastern region's carbon emissions decreased significantly in 2016. From the perspective of emission structure, petroleumbased energy is the main source of carbon emissions in China's logistics industry, and the consumption of coalbased and natural gas-based energy is very small.

Second, the calculation results of the Theil index show that, from 2010 to 2019, the inter-provincial differences in carbon emissions from China's logistics industry did not change substantially, and the overall trend was downward. The difference in carbon emissions between regions showed a slow upward trend, and the difference in carbon emissions within the region gradually decreased. In addition, the difference in carbon emissions between provinces in the eastern region was the largest, followed by the central region and then the western region. An obvious upward trend in the overall regional separation coefficient showed that the difference in carbon emissions between the three major regions gradually expanded.

Third, the Theil index contribution rate results showed that during the study period the Theil index contribution rate in the regions exhibited a gradual downward trend (average value of 0.8942), but this was substantially greater than the inter-regional Theil index contribution rate (average value of 0.1058). Among the three major regions, the contribution rate of the Theil index was the highest in the eastern region, followed by the central region, and the western region was the smallest. The above results show that the overall differences in carbon emissions in China's logistics industry were caused mainly by regional differences. Although the impact of regional differences on the overall difference has expanded, this remains significantly smaller than that of the intra-regional differences. The impact was greatest for the western region, for which this gap increased and the impact on the overall carbon emissions gap was the smallest.

Fourth, based on the LMDI decomposition model, the factors that caused changes in the carbon emissions of the logistics industry were decomposed into six driving factors: energy structure, energy efficiency, transportation mode, logistics output, economic development, and population size. The following conclusions can be drawn: (1) Economy. During the study period, the level of development was consistently the most important driving factor of the increase of the carbon emissions in the logistics industry, and the logistics output effect was the main factor that inhibited the increase in carbon emissions in the logistics industry. Therefore, when formulating carbon emission reduction measures in the logistics industry, it is necessary to fully consider the economic development levels of different regions and formulate differentiated carbon emission reduction strategies. It is also necessary to promote the large-scale development of the logistics industry to further enhance the positive effect of the logistics industry on economic development, to thereby exert the inhibitory effect of the logistics output effect. (2) The energy intensity effect in the three major regions is characterized by first promotion and then suppression, mainly because the energy intensity of the logistics industry in each region decreased during the study period. (3) The effects of energy structure and transportation mode are different in different regions. These are inhibitory effects in the east, but promotion effects in the eastern and central of China. The eastern region has a higher level of logistics interconnection, a more efficient transportation mode, and an optimized energy structure. This was particularly the case in recent years due to the use of new energy logistics vehicles and the development of multimodal transport in the eastern region. Therefore, in other regions, the use of new energy logistics vehicles should be increased, the energy consumption structure should be optimized, the level of logistics interconnection should be improved, and the development of multimodal transport should be promoted. (4) The population scale effect makes the smallest contribution to the carbon emissions of the logistics industry. Population had a negative effect in the western region, mainly because the population size of the western region slowly shrank during the study period.

In summary, in order to effectively reduce the level of carbon emissions in China's logistics industry and further promote the development of low-carbon logistics, this article puts forward the following recommendations: formulate carbon emission reduction policies, and promote regional development by participating in the formulation and gaming of carbon emission reduction and trading rules. Low-carbon development of the logistics industry; optimize the energy structure, improve transportation equipment, reduce the total carbon emissions of the logistics industry through the optimization and adjustment of the energy consumption structure and the improvement of transportation tools; develop multimodal transportation, optimize the transportation structure, and use different transportation methods Mutual coordination and 
reasonable organization within the same mode of transportation, optimize the transportation structure, improve the overall efficiency of the logistics industry in various regions, reduce the carbon emissions of the logistics industry, and achieve sustainable economic development; encourage technological innovation and promote energy conservation and emission reduction, Realize the low-carbon development of the logistics industry through technological innovation of transportation tools; actively explore the development and utilization of new energy, and the government should actively support the development and utilization of green energy in the logistics industry.

Although this article has achieved valuable research results, there are still some shortcomings, which are mainly reflected in the following aspects: (1) Lack of in-depth research on industry logistics. The logistics industry involves a wide range of areas, and every industry in the national economy has logistics.Due to industry differences, logistics in different industries have many differences in energy consumption and carbon dioxide emissions. This article is based on the logistics industry from a broad perspective, and does not reflect industry differences. In future research, it is necessary to conduct in-depth research in conjunction with industry logistics. (2) This article does not consider spatial spillover effects, and each influencing factor may have spatial spillover effects, so it needs to be demonstrated in further research. (3) As the current statistics of the logistics industry are not perfect and the available data is limited, some data need to be converted, sorted, and calculated, which affects the empirical results. If conditions permit, I hope that this research can be further improved to obtain more convincing conclusions.

\section{Acknowledgements}

This article is a funded project for the outstanding young backbone teachers of the 'Blue Project' in the Department of Education, Jiangsu Province, 2019.

\section{Conflict of Interest}

The authors declare no conflict of interest.

\section{References}

1. HU X.F., WANG X.H., WU S. Research on Carbon Emission Calculation and Driving Factors of Logistics Industry in the Yangtze River Economic Zone. Ecological Economy, 7, 49, 2019.

2. ZENG J., ZHOU Y. Analysis on the Spatial Differences in Carbon Emissions of China's Provincial Logistics Industry. Logistics Technology, 42 (6), 113, 2019.

3. WANG Y., MA M.X. Research on Carbon Emission Characteristics of Ningxia Logistics Industry under the Background of Energy Conservation and Emission Reduction. Journal of Northern University for Nationalities (Philosophy and Social Sciences Edition), 5, 153, 2019.

4. LU P., LU J.M. Analysis on the Influencing Factors and Countermeasures of Carbon Emissions in Guangxi Logistics Industry. National Business Information-Theoretical Research, 9, 26, 2019.

5. ZHANG J.L., LI C. Analysis of the difference in carbon emissions of the logistics industry in the Beijing-TianjinHebei region. Journal of North China Electric Power University: Social Science Edition, 117 (1), 53, 2019.

6. PETER C.,FIORE A., HAGEMANN U., NENDEL C. Improving the accounting of field emissions in the carbon footprint of agricultural products: a comparison of default IPCC methods with readily available medium-effort modeling approaches. The International Journal of Life Cycle Assessment, 21, 791, 2016.

7. LIPTOW C., JANSSEN M., TILLMAN A.M. Accounting for effects of carbon flows in LCA of biomass-based products - exploration and evaluation of a selection of existing methods. The International Journal of Life Cycle Assessment, 22, 1, 2018.

8. WANG X., ZHANG L.J, QIN Y.C. The temporal and spatial evolution of carbon emissions from China's highcarbon manufacturing industry and its driving factors. Resources Science, 42, 323, 2020.

9. CHEN F., ZHENG Y., DAI H.T. Research on Carbon Emissions of Inland Cities: Taking Hefei as an Example. Journal of Zhengzhou Institute of Aeronautical Industry Management, 38, 78, 2020.

10. LU Y. Analysis on the Dynamic Changes of Energy Consumption Carbon Emissions in Ningxia. Chinese and Foreign Entrepreneurs, 672, 251, 2020.

11. ZHOU Y.,WANG D.P.,ZHAO Y. $\mathrm{CO}_{2}$ emission measurement and low-carbon countermeasures of China's provincial logistics operations. China Population Resources and Environment, 9, 81, 2011.

12. ZHANG J., CAI J.F. Measurement and decomposition of regional differences in carbon emissions of China's logistics industry. China Circulation Economy, 28 (8), 25, 2014.

13. JIN F.H., FU L.Y., MA H.W. Research on the evolution of the spatial pattern of regional logistics carbon emissions. Science and Technology Management Research, 8, 254, 2016.

14. LENZEN M. Primary energy and greenhouse gases embodied in Aus-tralian final consumption: an inputoutput analysis. Energy Policy, 26 (6), 495, 1998.

15. MACHADO G., SCHAEFFER R., WORRELL E. Energy and carbon embodiedin the international trade of Brazil: an input-output approach.Ecological Economics, 39 (3), 409, 2001.

16. WEI Y.M., LIU L.C., FAN Y. The impact of lifestyle on energy useand $\mathrm{CO}_{2}$ emission: an empirical analysis of China's residents .Energy Policy, 35 (1), 247, 2007.

17. BURCHART-KOROL D. Significance of environmental life cycle assess-ment (LCA) method in the iron and steel industry . MetalurgijaSisak then Zagreb, 50 (3), 205, 2011.

18. BONILLA D., KELLER H., SCHMIELE J. Climate policy and solutions for green supply chains: Europe's predicament. Supply Chain Management: An International Journal, 20 (3), 249, 2015.

19. ANG B.W., LIU N. Handling zero values in the logarithmic mean Divisia index decomposition approach. Energy Policy, 35 (1), 77, 2005. 
20. CHUNBO M., DAVID I.S. China's Changing Energy Intensity Trend: A De-composition Analysis. Energy Economics, 30 (3), 1037, 2008.

21. CLAUDIA S.P., SERGIO M.P., GUILLERMO R.M.R. Decomposition of Energy Consumption and $\mathrm{CO}_{2}$ Emissions in Mexican Manufacturing Industries: Trends Between 1990 and 2008. Energy for Sustainable Development, 16 (1), 57, 2012.

22. LIU X.Z., YANG X. Research on Variable Screening of Influencing Factors of Carbon Emissions in China - Based on PLS-VIP Method. Environmental Ecology, 1, 60, 2020.

23. FAN Z.Y., ZHAO M.Z., GONG W.F.. Research on influencing factors and peaks of carbon emissions based on STIRPAT model: Taking Shandong Province as an example. Low Carbon Economy, 9, 100, 2020.

24. ZHANG L.G. Analysis on the driving factors of carbon dioxide emission changes in China's logistics industry. China Circulation Economy, 30 (12), 29, 2016.

25. MA Y.Y., WANG W.G. Analysis of Carbon Emission Characteristics and Influencing Factors of China's Logistics Industry-Based on LMDI Decomposition Technology. The Practice and Understanding of Mathematics, 43 (10), 31, 2013.

26. YUAN Q.M., ZHANG W.L., NING N.N. Research on the driving factors and decoupling effects of carbon emission in the logistics industry in Beijing-Tianjin-Hebei. Science and Technology Management Research, 5, 222, 2016.

27. LIU L.Z., LIU P. Research on the Correlation between the Development of the Logistics Industry and Carbon Emissions and Energy Consumption - Taking Fujian Province as an example. Market Forum, 12, 34, 2014.

28. TANG J.R., LI L.Z. Analysis of logistics efficiency under low-carbon constraints: taking ten eastern provinces and cities as examples. China Circulation Economy, 1, 42, 2013.

29. ROBERTO E. Is there cross-country convergence in carbon dioxide emissions?. Energy Policy, 35 (2), 454, 2006.

30. CLARK-SATHER A., QU J., WANG Q. Carbon inequality at the sub-national scale: A case study of provincial-level inequality in $\mathrm{CO}_{2}$ emissions in China 1997-2007. Energy Policy, 39 (9), $5420,2011$.

31. ZHOU G.H., CHUNG W., ZHANG X.L. A study of carbon dioxide emissions performance of China's transport sector. Energy, 50 (3), 302, 2013.
32. YAO C.R., FENG K.S., KLAUS H. Driving forces of $\mathrm{CO}_{2}$ emissions in the G20 countries: An index decomposition analysis from 1971 to 2010. Ecological Informatics, 26, 55, 2015.

33. LIU Z.C., WANG A.J., YU W.J. Research on Regional Carbon Emissions in China. Acta Geosciences, 31 (5), 727, 2010.

34. ZHANG L., HUANG Y.X., LI Y.M. China's carbon emission regional pattern change and analysis of emission reduction approaches. Resources Science, 32 (2), 211, 2010.

35. DENG J.X., LIU X., WANG Z. Analysis and factor decomposition of regional differences and evolution characteristics of China's carbon emissions. Journal of Natural Resources, 29 (2), 189, 2014.

36. ZHANG L.G., LI D., ZHOU D.Q. The dynamic changes and regional differences of carbon dioxide emission performance in China's logistics industry-an empirical analysis based on provincial panel data. System Engineering, 31 (4), 95, 2013.

37. LUO F., GUO Y., WEI W.D. The decoupling relationship between carbon emissions and economic growth in the Yangtze River Economic Zone: Based on the perspective of production and consumption. China Environmental Science, 40, 1364, 2020.

38. LIANG W., FANG S.H. Research on the dynamic relationship between logistics industry growth, urbanization and carbon emissions. Jianghan Academic, 38 (4), 73, 2019.

39. GAO K.B., WANG Y.G., LI X.C. Research on the Influencing Factors of Transportation Carbon Emissions in Henan Province Based on GRA. Logistics Technology, 42 (4), 74, 2019.

40. WANG L.P., LIU M.H. Research on Carbon Emission Calculation and Influencing Factors of China's Logistics Industry Based on Input-Output Method. Resources Science, 1, 195, 2018.

41. WANG J.Y. Numerical simulation analysis of dynamic evolution of carbon emission characteristics of aviation logistics transportation. Environmental Science and Management, 44 (4), 54, 2019.

42. LIU Y. Research on the Decomposition and Decoupling Effect of Carbon Emission Driving Factors in the Logistics Industry under the Condition of Open Economy: Taking Shaanxi Province as an Example. Ecological Economy, 11, 84, 2018. 